\title{
Tái cấu trúc quá trình kinh doanh và các công cụ hỗ trọ:: Tổng quan cơ sở lý thuyết
}

\section{Business process reengineering and supporting tools: A literature review}

\author{
Nguyễn Thúy Quỳnh Loan ${ }^{1 *}$ \\ ${ }^{1}$ Trường Đại học Bách khoa, Đại học Quốc gia Thành phố Hồ Chí Minh, Việt Nam \\ *Tác giả liên hệ, Email: ntqloan@ @cmut.edu.vn
}

THÔNG TIN

DOI: $10.46223 /$ HCMCOUJS. econ.vi.14.1.495.2019

Ngày nhận: 06/12/2018

Ngày nhận lại: 23/12/2018

Duyệt đăng: 14/01/2019

Tù khóa:

công cụ hỗ trợ, quản lý chất lượng toàn diện (TQM), tái cấu trúc quá trình kinh doanh (BPR), tích hợp

Keywords:

business process reengineering (BPR), integration, supporting tools, total quality management (TQM)
TÓM TẮT

Mục tiêu của bài báo này là phân tích tổng quan cơ sở lý thuyết về tái cấu trúc quá trình kinh doanh (BPR) và các công cụ hỗ trợ nhằm tạo điều kiện thuận lợi cho các doanh nghiệp Việt Nam khi triển khai BPR. Tổng quan lý thuyết về BPR gồm các khái niệm, các quá trình kinh doanh, vai trò của công nghệ thông tin, khi nào thực hiện, so sánh giữa $\mathrm{BPR}$ và TQM, kinh nghiệm thực hiện trên thế giới và Việt Nam, các bước thực hiện. Ngoài ra, bài báo cũng tích hợp các công cụ và kỹ thuật hỗ trợ theo từng bước của $\mathrm{BPR}$, đó là $\mathrm{SWOT}$, bản đồ chiến lược, chuẩn đối sánh, DMAIC, FMEA, QFD, Kaizen, $5 \mathrm{~S}, \mathrm{VSM}, 7$ công cụ chất lượng. Kết quả của bài báo này sẽ là cơ sở để nhóm nghiên cứu triển khai thử nghiệm việc thực hiện BPR tại một số doanh nghiệp ở Việt Nam trong giai đoạn tiếp theo.

ABSTRACT
This paper aims to review the literature on business
process reengineering and its supporting tools to facilitate
Vietnamese enterprises in BPR implementation. The literature
review on BPR includes concepts, business processes, the role
of information technology, time for implementing BPR,
comparison between BPR and TQM, experiences of BPR
implementation in the world and Vietnam, BPR steps. Besides,
the paper integrates the supporting tools and techniques in
each BPR step, including SWOT, strategy map,
benchmarking, DMAIC, FMEA, QFD, Kaizen, 5S, VSM, 7
basic quality tools. The research findings will enable
researchers to pilot the implementation of BPR projects in
some Vietnamese enterprises in the next stage.




\section{Giới thiệu}

Xu hướng toàn cầu hóa và tự do hóa thương mại đã làm cho sự cạnh tranh trở nên ngày càng gay gắt. Điều này tạo ra áp lực phải có sự thay đổi của tổ chức, nơi mà toàn bộ quá trình và môi trường làm việc và cơ cấu tổ chức phải được thay đổi (Lilian, Uzochukwu, \& Francisca, 2015). Việc triển khai nhanh chóng các công nghệ mới, toàn cầu hóa hoạt động kinh doanh và sự kỳ vọng của khách hàng liên tục thay đổi là những tác nhân chính đằng sau sự biến đổi này. Các tổ chức hiện tại muốn thành công trong môi trường kinh doanh đầy thách thức này, họ cần phải xác định lại chiến lược nhằm giảm thiểu chi phí dịch vụ và sản phẩm cũng như cải thiện sự hài lòng của khách hàng, chất lượng dịch vụ và sự hài lòng công việc (Gamar \& Agrawal, 2015). Trong bối cảnh Việt Nam, các doanh nghiệp đang phải chịu áp lực cả bên trong lẫn bên ngoài doanh nghiệp. Áp lực bên trong là do sự phát triển như quy mô doanh nghiệp lớn lên nhanh chóng, phạm vi hoạt động rộng hơn, lĩnh vực hoạt động kinh doanh đa dạng hơn; hay do vận hành không hiệu quả như thiếu chiến lược và thiếu tập trung, thiếu hụt nguồn nhân lực... Các áp lực bên ngoài là do sự hội nhập của Việt Nam vào tổ chức thương mại thế giới (WTO), cộng đồng kinh tế ASEAN (AEC), hay hiệp định thương mại hàng hóa ASEAN...

Trước những áp lực này, các tổ chức bao gồm cả doanh nghiệp Việt Nam cần phải đánh giá lại nhiệm vụ/sứ mạng, mục tiêu chiến lược, và nhu cầu khách hàng. Chỉ sau khi suy nghĩ lại, doanh nghiệp sẽ nhận ra những gì cần phải làm, và quyết định cách thực hiện thay đổi phù hợp nhất. Tái cấu trúc quá trình kinh doanh (Business Process Reengineering - BPR) là một công cụ phổ biến trên thế giới và có giá trị chiến lược trong quản lý sự thay đổi tổ chức về tầm nhìn hay chiến lược mới: cần xây dựng năng lực hoạt động, đánh giá lại lựa chọn chiến lược, tham gia thị trường mới hoặc xác định lại sản phẩm/dịch vụ và phản ánh chiến lược tổng thể của công ty (Goksoy, Ozsoy, \& Vayvay, 2012). BPR là tư duy lại nền tảng và thiết kế lại các công việc để hỗ trợ tốt hơn nhiệm vụ của tổ chức và giảm chi phí. Nghĩa là, BPR liên quan đến việc loại bỏ đi những quá trình cũ và tìm cách sáng tạo cho công việc, thiết kế lại hoàn toàn và đưa ra quá trình mới. BPR là một giải pháp cho các doanh nghiệp để cải thiện hoạt động của mình bằng việc đảm bảo tạo ra sản phẩm chất lượng cao với chi phí thấp, giá trị gia tăng lớn hơn và thời gian phản ứng nhanh hơn, nâng cao hiệu quả hoạt động và đạt được một lợi thế cạnh tranh (Siha \& Saad, 2008). BPR có thể được xem là một trong những phương pháp quản lý thay đổi cho các tổ chức vì a) BPR chú trọng đến đổi mới và cải tiến, b) Thiết kế lại quá trình và công nghệ thông tin $(\mathrm{CNTT})$ là những thành phần thiết yếu của $\mathrm{BPR}$ và đó cũng là nền tảng của kinh doanh ngày nay, c) BPR hỗ trợ việc cải thiện vấn đề về chi phí, chất lượng, dịch vụ và tốc độ tăng trưởng (Goksoy et al., 2012). Mục tiêu của BPR không chỉ là cải thiện chi phí và hiệu suất, mà còn thay đổi văn hóa tổ chức và đưa đến việc kiểm soát cho các quá trình kinh doanh (Ozcelik, 2010).

Trên thế giới có nhiều nghiên cứu về việc triển khai thành công các dự án BPR (Asli \& Özalp, 2010; Attaran, 2004; Rootinc, 2012), tuy nhiên khái niệm BPR còn khá mới mẻ với các doanh nghiệp Việt Nam. Do đó, các nghiên cứu về BPR còn hạn chế ở Việt Nam. Chính vì vậy trong nghiên cứu của Bui và Nguyen (2016) đã đề xuất lộ trình thực hiện BPR cho các doanh nghiệp vừa và nhỏ Việt Nam. Khi triển khai thử nghiệm $B P R$ tại một số doanh nghiệp Việt Nam, nhóm nghiên cứu của Bui và Nguyen (2016) nhận thấy doanh nghiệp gặp khó khăn khi lựa chọn công cụ hỗ trợ cho thực hiện BPR. Từ đó, mục tiêu của bài báo này là tổng quan cơ sở lý thuyết về tái cấu trúc quá trình kinh doanh và các công cụ hỗ trợ nhằm tạo điều kiện thuận 
lợi cho các doanh nghiệp Việt Nam khi triển khai các dự án BPR. Để đạt được mục tiêu này, phương pháp nghiên cứu bàn giấy đã được áp dụng. Bài báo đã tham khảo các nghiên cứu trước, sau đó tóm tắt, đối chiếu/so sánh, tổng hợp các tài liệu thứ cấp và đưa ra những nhận định hay bàn luận.

\section{Tái cấu trúc quá trình kinh doanh}

\subsection{Khái niệm}

Trước tiên cần phân biệt khái niệm giữa Restructruring và Reengineering. "Restructuring" (thường được dịch là tái cơ cấu) là quá trình chuyển đổi từ cơ cấu tổ chức hiện tại sang cơ cấu mới (thị trường, sản xuất, công nghệ, tài chính, tổ chức, nhân sự, sở hữu, sinh thái, phát triển) cho phép hoạt động doanh nghiệp thành công và hiệu quả cao hơn. Tái cơ cấu là một trong những phương pháp thay đổi mang tính cách mạng (Dubrovski, 2005). Mục tiêu chính tái cơ cấu (Restructruring) là thay đổi cơ cấu trong tổ chức, trong khi đó Reengineering (thường được dịch là tái cấu trúc/tái lập) là việc tu duy lại nền tảng và thiết kế lại căn bản các quá trình kinh doanh nhằm đạt được những cải thiện đáng kể về các kết quả thực hiện quan trọng như là chi phí, chất lượng, dịch vụ và tốc độ (Hammer \& Champy, 1993). Restructruring cũng giống như Reengineering là phương pháp thay đổi mang tính cách mạng và do đó chúng thể hiện tất cả các đặc điểm chung của những thay đổi triệt để. Reengineering and Restructuring không phải là phương pháp không tương thích lẫn nhau mặc dù chúng điểm xuất phát khác nhau, và trong một tổ chức chúng có thể thực hiện song song với nhau hoặc thậm chí được đan xen (Dubrovski, 2005). Trong bài báo này chỉ đề cập tới khái niệm Reengineering và được tạm dịch là tái cấu trúc/tái lập.

BPR nổi lên ở Mỹ trong thập niên 1980 và đầu thập niên 1990. Có nhiều định nghĩa BPR được thực hiện bởi các học giả khác nhau. Davenport và Short (1990) định nghĩa BPR là sự phân tích và thiết kế lại các dòng công việc và quá trình trong và giữa các tổ chức. Theo GAO (1997), BPR là một công cụ giúp doanh nghiệp xem xét lại cách họ hoạt động nhằm tạo ra sự cải thiện hiệu quả trong dịch vụ khách hàng, cắt giảm chi phí hoạt động và vươn lên thành đối thủ cạnh tranh tầm quốc tế. BPR là cách tiếp cận mạnh mẽ để mang lại những cải tiến vuợt bậc trong đầu ra của một tổ chức. Điều này đạt được thông qua những thay đổi căn bản trong các quá trình, đó là những mấu chốt thành công cho doanh nghiệp (Sanjay, 2013). Petrozzo và Stepper (1994) tin rằng $\mathrm{BPR}$ liên quan đến việc thiết kế lại đồng thời các quá trình, tổ chức và hệ thống thông tin hỗ trợ của họ để đạt được sự cải thiện căn bản về thời gian, chi phí, chất lượng và sự quan tâm của khách hàng đối với các sản phẩm và dịch vụ của công ty. Điểm quan trọng của định nghĩa này là đề cập đến hệ thống thông tin. Trong khi đó, một số tác giả cho rằng $\mathrm{BPR}$ không nhất thiết phải phụ thuộc vào các giải pháp CNTT nhưng họ đồng ý rằng CNTT có thể là một yếu tố hỗ trợ mạnh mẽ và tạo ra cải tiến triệt để khi thiết kế lại quá trình hoạt động của tổ chức (Gadd \& Oakland, 1996; Hammer \& Champy, 1993).

Từ các định nghĩa trên, các nội hàm chính được thể hiện trong khái niệm BPR gồm:

- Tu duy lại nền tảng: nghĩ suy lại những gì công ty đã làm, tại sao nó được thực hiện theo cách hiện tại, các quy tắc và giả định khi thực hiện chúng là gì. Tái cấu trúc bỏ qua "Nó là gi” mà tập trung vào "Nó nên là gì" (Hammer \& Champy, 1993). Việc này sẽ thách thức với các giả định cũ và loại bỏ các quy tắc cũ không còn phù hợp nữa (Adeyemi \& Aremu, 2008).

- Thiết kế lại căn bản: tạo ra/phát minh lại cách thực hiện mới - không thực hiện các 
thay đổi bề ngoài hoặc cải tiến cho những cách thực hiện cũ (Hammer \& Champy, 1993).

- Quá trình (Process): là một tập hợp các hoạt động được đo lường và có cấu trúc được thiết kế để tạo ra một đầu ra xác định cho một khách hàng hoặc thị trường cụ thể. Nó nhấn mạnh đến cách thức thực hiện công việc trong một tổ chức (Davenport, 1993).

- Quá trình kinh doanh (Business process): gồm có 3 thành phần là đầu vào (dữ liệu về yêu cầu của khách hàng hoặc nguyên vật liệu), xử lý (xử lý dữ liệu yêu cầu của khách hàng hoặc nguyên vật liệu), và kết quả (phân phối các kết quả mong đợi tới khách hàng nội bộ và bên ngoài). Các vấn đề của quá trình chính là ở bước xử lý. BPR can thiệp vào bước xử lý, nghĩa là bước này sẽ được tái cấu trúc/tái lập để làm giảm thời gian và tiền bạc (Zygiaris, 2000). Bảng 1 trình bày các quá trình kinh doanh có thể thực hiện BPR trong doanh nghiệp (Lilian et al., 2015).

- Cải tiến vượt bậc/đáng kể: tạo ra bước nhảy vọt hay thay đổi đáng kể về kết quả thực hiện - không phải là cải tiến gia tăng (Hammer \& Champy, 1993).

\section{Bảng 1}

Các quá trình kinh doanh trong doanh nghiệp

\begin{tabular}{|l|l|}
\hline Chức năng & \multicolumn{1}{c|}{ Các quá trình kinh doanh } \\
\hline Vận hành & $\begin{array}{l}\text { Mua sắm, Quản lý đơn đặt hàng, Lập hóa đơn, Vận chuyển, Xử lý hoàn chỉnh đơn } \\
\text { hàng, Sản xuất, Quản lý kho, Lập kế hoạch sản xuât, Lập kế hoạch điều độ nâng } \\
\text { cao, Hoạch định nhu cầu, năng lực }\end{array}$ \\
\hline Nhân lực & $\begin{array}{l}\text { Xử lý thời gian và chi phí, Xử lý lương, Quản lý hiệu suất, Tuyển dụng, Thuê } \\
\text { mướn, Lập kế hoạch kế nhiệm, Quản lý lợi ích, Đánh giá năng lực }\end{array}$ \\
\hline $\begin{array}{l}\text { Quan hẹ } \\
\text { khách hàng }\end{array}$ & $\begin{array}{l}\text { Dịch vụ khách hàng qua mạng, Dịch vụ chăm sóc khách hàng, Quản lý vấn đề̀, } \\
\text { Yều của khách hàng, Quản lý kênh bán hàng, Thực hiện dịch vụ }\end{array}$ \\
\hline $\begin{array}{l}\text { Tiếp thị và } \\
\text { bán hàng }\end{array}$ & $\begin{array}{l}\text { Quản lý tài khoản, Nghiên cứu phân tích và thị trường, Tiếp thị sản phẩm/thương } \\
\text { hiệu, Quản lý chương trình, Quản lý lắp đặt, Lập kế hoạch hoa hồng bán hàng, } \\
\text { Thu nhận khách hàng, Lập kế hoạch bán hàng }\end{array}$ \\
\hline Tài chính & $\begin{array}{l}\text { Lợi nhuận của sản phẩm, Ủy quyền tín dụng, Quản lý tiền mặt, Kiểm toán nội bộ, } \\
\text { Thu hồi nợ, Hàng tồn kho, Kiểm tra xử lý yêu cầu, Chi phí vốn, Quản lý tài sản }\end{array}$ \\
\hline
\end{tabular}

Nguồn: Lilian và cộng sự (2015)

\subsection{Vai trò của công nghệ thông tin trong BPR}

Việc thực hiện BPR nhấn mạnh đến sự thay đổi căn bản, CNTT được xem là yếu tố then chốt cho sự thay đổi này (Hammer \& Champy, 1993). Vai trò CNTT có thể được phân loại thành ba giai đoạn khi thực hiện BPR (Attaran, 2004): trước thiết kế quá trình, trong thiết kế quá trình và sau khi thiết kế hoàn thành (Bảng 3 ).

\section{Bảng 2}

Vai trò CNTT trong việc khởi tạo và duy trì $\mathrm{BPR}$

\begin{tabular}{|c|c|c|}
\hline $\begin{array}{c}\text { Trước thiết kế } \\
\text { quá trình }\end{array}$ & Trong khi thiết kế quá trình & $\begin{array}{c}\text { Sau khi thiết kế } \\
\text { hoàn thành }\end{array}$ \\
\hline Tạo cơ sở hạ tầng và & Mang lại lượng thông tin khổng lồ vào & Tạo vòng phản hồi kỹ \\
\hline
\end{tabular}




\begin{tabular}{|c|c|c|}
\hline $\begin{array}{c}\text { Trước thiết kế } \\
\text { quá trình }\end{array}$ & Trong khi thiết kế quá trình & $\begin{array}{l}\text { Sau khi thiết kế } \\
\text { hoàn thành }\end{array}$ \\
\hline $\begin{array}{l}\text { quản lý thông tin } \\
\text { Khuyến khích tư duy } \\
\text { quá trình } \\
\text { Xác định và chọn quá } \\
\text { trình thiết kế lại } \\
\text { Tham gia dự đoán bản } \\
\text { chất của thay đổi và dự } \\
\text { đoán thông tin cần hổ } \\
\text { trợ cho thay đồi đó } \\
\text { Giáo dục nhân viên } \\
\text { CNTT trong các vấn } \\
\text { đề phi kỹ thuật như } \\
\text { tiếp thị, quan hệ khách } \\
\text { hàng... } \\
\text { Tham gia thiết kế các } \\
\text { biện pháp thành công } \\
\text { trong BPR }\end{array}$ & $\begin{array}{l}\text { quá trình } \\
\text { Mang theo các phương pháp phân tích } \\
\text { phức tạp trong quá trình } \\
\text { Nâng cao khả năng của nhân viên để đưa } \\
\text { ra quyết định sáng suốt hơn mà ít phụ } \\
\text { thuộc vào luồng thông tin dọc chính thức } \\
\text { Xác định tác nhân cho thiết kế quá trình } \\
\text { Nắm bắt bản chất của thay đổi được đề } \\
\text { xuât và kêt hợp chiến lược CNTT } \\
\text { Nắm bắt và phổ biến kiến thức, chuyên } \\
\text { môn đề cải thiện quá trình } \\
\text { Truyền đạt kết quả liên tục của nỗ lực } \\
\text { BPR } \\
\text { Chuyển đổi các quá trình phi cấu trúc } \\
\text { thành các giao dịch được thực hiện định } \\
\text { kỳ } \\
\text { Giảm/thay thế lao động trong quá trình } \\
\text { Đo lường kết quả thực hiện của quá trình } \\
\text { hiện tại } \\
\text { Xác định các mục tiêu và kết quả thực } \\
\text { hiện rõ ràng để thúc đâyy việc triển khai } \\
\text { Xác định phạm vi của quá trình }\end{array}$ & $\begin{array}{l}\text { thuật số } \\
\text { Thiết lập các nguồn lực để } \\
\text { đánh giá BPR } \\
\text { Cải tiến các quá trình } \\
\text { CNTT để đáp ứng nhu } \\
\text { cầu ngày càng tăng của } \\
\text { các bộ phận thực hiện } \\
\text { BPR } \\
\text { Kiểm soát tổn thất trong } \\
\text { trường hợp thất bại } \\
\text { Truyền đạt kết quả liên } \\
\text { tục của nồ lực BPR } \\
\text { Giúp xây dựng cam kết } \\
\text { với BPR } \\
\text { Đánh giá đầu tư và lợi } \\
\text { nhuận tiềm năng của các } \\
\text { nỗ lực BPR }\end{array}$ \\
\hline
\end{tabular}

Nguồn: Attaran (2004)

\subsection{Khi nào thục hiện BPR}

Nhiều nghiên cứu cho thấy các lý do chính để thực hiện BPR khi các tổ chức muốn:

- Cải tiến quá trình và nâng cao chất lượng (Carr \& Johansson, 1995; Lilian et al., 2015; Samia \& Germaine, 2008; Zygiaris, 2000).

- Nâng cao khả năng mở rộng sang các ngành khác (Lilian et al., 2015).

- Đáp ứng khách hàng, nhân viên, và các bên liên quan (Carr \& Johansson, 1995; Lilian et al., 2015; Samia \& Germaine, 2008).

- Tạo sản phẩm/dịch vụ khác biệt đáng kể (Lilian et al., 2015; Zygiaris, 2000).

- Tăng thị phần, cải thiện lợi nhuận (Carr \& Johansson, 1995; Samia \& Germaine, 2008).

- Giảm chi phí (Carr \& Johansson, 1995; Zygiaris, 2000).

- Giảm thời gian phát triển và sản xuất sản phẩm (Carr \& Johansson, 1995; Samia \& Germaine, 2008; Zygiaris, 2000).

- Cạnh tranh (Lilian et al., 2015). 
- Đáp ứng với một kỷ nguyên của sự thay đổi (Lilian et al., 2015; Zygiaris, 2000).

- Tồn tại và thành công trong dài hạn (Lilian et al., 2015).

- Phát minh ra "quy tắc của trò chơi" mới (Lilian et al., 2015).

\subsection{BPR và TQM}

Một tổ chức thực hiện quản lý chất lượng toàn diện (TQM - Total Quality Management) là một tổ chức hoạt động với các giá trị và khái niệm cơ bản nhất định, bao gồm chất lượng định hướng khách hàng, lãnh đạo tích cực, cải tiến và học tập liên tục, sự tham gia và phát triển của nhân viên, phản hồi nhanh, chất lượng thiết kế và ngăn ngừa tổn thất, một tầm nhìn dài, quản lý dựa trên sự kiện, phát triển quan hệ đối tác, trách nhiệm của công ty và quyền công dân, định hướng vào quá trình và kết quả (Bui \& Nguyen, 2017). Nhấn mạnh của TQM là các lợi ích do cải tiến liên tục và tăng dần, trong khi đó nhấn mạnh của BPR là cải thiện kết quả thực hiện độc đáo và ấn tượng thông qua việc thiết kế lại quá trình.

$\mathrm{BPR}$ có thể được xem như là dựa trên $\mathrm{TQM}$. Khi thay đổi quá trình thì $\mathrm{BPR}$ được xem là căn bản hơn TQM, do đó nên tích hợp cả $\mathrm{BPR}$ và TQM trong một tổ chức (Chang, 1994; Furey, 1993; Gadd \& Oakland, 1996). Nói cách khác, BPR và TQM có thể cùng tồn tại và hỗ trợ cho nhau trong mục đích cải tiến quá trình trong một tổ chức. Có lẽ sự khác biệt nhất giữa BPR và TQM là một vấn đề về mức độ thay đổi (Cole, 1994), trong khi một số lượng lớn các đặc điểm giữa $T Q M$ và $B P R$ là tương tự nhau. Do đó, việc sử dụng các công cụ của TQM khi thực hiện $\mathrm{BPR}$ được xem là một tiếp cận tốt cho các doanh nghiệp có nền tảng về TQM. Hơn nữa, sau khi thực hiện BPR bước tiếp theo là cải tiến liên tục dựa trên TQM. Tuy nhiên, điều này không có nghĩa là doanh nghiệp chưa thực hiện TQM không thể thực hiện thành công $\mathrm{BPR}$. Theo nghiên cứu của Bui và Nguyen (2016) tại một số doanh nghiệp của Việt Nam, doanh nghiệp đã thực hiện TQM khi triển khai BPR gặp nhiều thuận lợi và kết quả đạt được có những thay đổi đáng kể. Trong khi đó doanh nghiệp chưa thực hiện TQM gặp khá nhiều khó khăn khi ban đầu ban lãnh đạo chưa hiểu rõ mục đích và lợi ích của BPR cũng như việc ứng dụng các công cụ của TQM. Điều này là cho việc thực hiện $\mathrm{BPR}$ mất nhiều thời gian hơn, nhưng nhìn chung kết quả đạt được cũng có thay đổi theo hướng tích cực.

\subsection{Kinh nghiệm trên thế giới và Việt Nam khi triển khai BPR}

Chìa khóa để thực hiện BPR thành công cần phải tuân thủ các hướng dẫn sau (Hammer \& Champy, 1993):

Luôn bắt đầu với khách hàng: Các quá trình kinh doanh tồn tại chỉ vì mục đích làm hài lòng khách hàng. Vì vậy, điểm then chốt của BPR là tổ chức lại nguồn lực của công ty hướng đến mục tiêu đáp ứng nhu cầu của khách hàng. Cách tốt nhất để tạo ra sự hăng hái cho một chương trình $\mathrm{BPR}$ là thiết lập những mục tiêu đầy tham vọng để mở rộng và thách thức cho tổ chức. Mọi người sẽ không có động lực từ bỏ sự quen thuộc và áp dụng BPR trừ khi họ được truyền cảm hứng bởi tầm nhìn của tổ chức sẽ trở thành gì.

Thưc hiện nhanh: BPR phải được hoàn thành nhanh chóng và dứt khoát, nếu không các lực lượng chống đối nội bộ sẽ áp đảo và cản trở việc thực hiện. Dự án BPR phải được thực hiện nhanh chóng - nhanh hơn và tốt hơn. Kinh nghiệm cho thấy khoảng 12 tháng là một cơ hội tốt cho một dự án BPR thành công.

Chấp nhận rủi ro: Thay đổi luôn bao gồm cả rủi ro. Vì vậy, khi thực hiện BPR, những người bản chất không thích rủi ro sẽ cảm thấy mất phương hướng và không ủng hộ cho sự thay 
đổi. Kinh nghiệm cho thấy cách duy nhất để bù đắp sự lo sợ khi sự thay đổi trong một tổ chức là chứng minh những rủi ro lớn hơn sẽ gặp phải tổ chức vẫn vận hành như hiện tại. Nếu mọi người được thuyết phục rằng "kinh doanh như thông thường" thì tổ chức sẽ gặp phải thất bại sớm, khi đó buộc họ phải thay đổi mặc dù sẽ có thể gặp nhiều khó khăn.

Chấp nhận sụ không hoàn hảo trong lúc thực hiện: Không có chương trình BPR nào thành công một cách hoàn hảo ngay từ lúc ban đầu. BPR luôn là một quá trình lặp đi lặp lại nơi một cái mới sẽ được đưa vào và mở rộng ra nếu nó hoạt động đem lại hiệu quả tốt hơn. Nhưng khi thay đổi nó cũng có thể sẽ thất bại một phần trong lúc thực hiện, đây là điều bình thường. Điều quan trọng không phải là tránh những sai lầm mà là học hỏi từ sai lầm và đi lên.

Đùng dùng lại quá sớm: Có những tổ chức tạm dừng BPR khi họ thấy những dấu hiệu đầu tiên của sự thành công. Nhưng cũng có những tổ chức dừng lại ở những dấu hiệu đầu tiên của sự không thành công. Cả hai hành động này đều gây tổn hại cho sự thành công dài hạn của tổ chức. Các bước đột phá thực sự đòi hỏi sự kiên trì và kiên nhẫn.

Theo Chang, Levy, và Powell (2009), các yếu tố thành công đối với các doanh nghiệp nhỏ và vừa của Đài Loan là định hướng chiến lược của công ty, cam kết của lãnh đạo cấp cao và quan hệ bên ngoài với khách hàng. Ngoài ra, hệ thống thông tin được tích hợp với định hướng chiến lược cũng là yếu tố cần thiết cho sự thành công. Còn đối với một số doanh nghiệp Việt Nam (Bui \& Nguyen, 2016) là sự cam kết và quyết tâm của lãnh đạo cấp cao, thực hiện liên tục và luôn bắt đầu từ khách hàng, sự tham gia của các cấp quản lý, chấp nhận sự không hoàn hảo khi thực hiện, thực thi nhanh.

Ngoài ra, các tổ chức cũng cần phải quan tâm đến các yếu tố thành công và thất bại khi thực hiện BPR được tổng hợp trong Bảng 4 . Các yếu tố này được phân thành 5 nhóm: quản lý thay đổi và văn hóa, năng lực quản lý và hỗ trợ, cơ cấu tổ chức, quản lý dự án $B P R$, cơ sở hạ tầng CNTT. Một số tình huống triển khai BPR thành công trên thế giới và Việt Nam cũng được tổng hợp trong Bảng 5 . Dựa trên những kinh nghiệm này các doanh nghiệp cần có những kế hoạch chuẩn bị trước để chọn quá trình kinh doanh phù hợp cho việc thực hiện tái cấu trúc và phát huy tốt các yếu tố thành công cũng như giảm thiểu các yếu tố thất bại tác động khi thực hiện BPR. Đặc biệt, các doanh nghiệp cần xem ứng dụng của CNTT để đem lại những thay đổi lớn cho quá trình.

\section{Bảng 3}

Các yếu tố thành công và thất bại khi triển khai BPR

\begin{tabular}{|c|c|}
\hline Các yếu tố thành công & Các yếu tố thất bại \\
\hline \multicolumn{2}{|c|}{ Quản lý thay đổi và văn hóa } \\
\hline $\begin{array}{l}\text { - Hệ thống khen thuởng (Al-Mashari \& Zairi, 1999; } \\
\text { Chang, Levy, \& Powell, 2010; Habib, 2013; Hassan- } \\
\text { gholipour, Abbaszadeh, \& Abtahi, 2013) } \\
\text { - Giao tiếp (Al-Mashari \& Zairi, 1999; Habib, 2013; } \\
\text { Hasnan, Ringim, \& Razalli, 2017; Hassan-gholipour et } \\
\text { al., 2013) } \\
\text { - Trao quyền (Al-Mashari \& Zairi, 1999; Change et } \\
\text { al., 2006; Chang et al., 2010; Goksoy et al., 2012; Habib, }\end{array}$ & $\begin{array}{l}\text { - Có vấn đề trong giao tiếp (Al- } \\
\text { Mashari \& Zairi, 1999; Habib, 2013; } \\
\text { Hasnan et al., 2017) } \\
\text { - Cản trở trong tổ chức (Al- } \\
\text { Mashari \& Zairi, 1999; Habib, 2013; } \\
\text { Hasnan et al., 2017; Hassan- } \\
\text { gholipour et al., 2013) } \\
\text { - Thiếu sứ sắn sàng cho sụ thay đổi } \\
\text { của tố chức (Al-Mashari \& Zairi, }\end{array}$ \\
\hline
\end{tabular}




\begin{tabular}{|l|}
\hline Các yếu tố thành công \\
\hline 2013; Hassan-gholipour et al., 2013) \\
- Sư tham gia của mọi ngưòi (Al-Mashari \& Zairi, \\
1999; Habib, 2013; Hassan-gholipour et al., 2013; Omidi \\
\& Khoshtinat, 2016) \\
- Đào tạo và giáo dục (Al-Mashari \& Zairi, 1999; \\
Habib, 2013; Hassan-gholipour et al., 2013; Herzog, \\
Polajnar, \& Tonchia, 2007; Omidi \& Khoshtinat, 2016) \\
- Văn hóa thay đổi, sáng tạo (Al-Mashari \& Zairi, \\
1999; Goksoy et al., 2012; Hasnan et al., 2017; Omidi \& \\
Khoshtinat, 2016) \\
- Khuyến khích tiếp thu cái mói (Al-Mashari \& Zairi, \\
1999; Hasnan et al., 2017; Omidi \& Khoshtinat, 2016)
\end{tabular}

Năng lực quản lý và hỗ trợ

- Cam kết và lãnh đạo mạnh mẽ (Al-Mashari \& Zairi, 1999; Bui \& Nguyen, 2016; Chang et al., 2010; Habib, 2013; Hasnan et al., 2017; Herzog et al., 2007; Ursic, Anteric, \& Mulej, 2005)

- Theo đuổi sụ thay đổi và tài trọ (Al-Mashari \& Zairi, 1999; Hasnan et al., 2017)

\section{Các yếu tố thất bại}

1999; Habib, 2013)

- Các vấn đề về văn hóa cho sụ thay đổi (Al-Mashari \& Zairi, 1999; Habib, 2013)

- Thiếu đào tạo và giáo dục (AlMashari \& Zairi, 1999; Habib, 2013)

- Quản lý rủi ro (Al-Mashari \& Zairi, 1999)

- Kiến thức của nhà quản lý về BPR (Habib, 2013; Hassan-gholipour et al., 2013)

Cơ cấu tổ chức

- Tiếp cận tích hợp công việc một cách đầy đủ (AlMashari \& Zairi, 1999; Omidi \& Khoshtinat, 2016)

- Các nhóm BPR hiệu quả (Al-Mashari \& Zairi, 1999; Chang et al., 2010; Goksoy et al., 2012; Hassangholipour et al., 2013; Habib, 2013; Herzog et al., 2007)

- Định nghĩa công việc phù hợp và phân bổ trách nhiệm (Al-Mashari \& Zairi, 1999; Hasnan et al., 2017)

- Cấu trúc it quan liêu (phẳng hơn) (Goksoy et al., 2012; Hasnan et al., 2017)
- Thiếu cam kết, hỗ trợ và lãnh đao (Al-Mashari \& Zairi, 1999; Habib, 2013; Hasnan et al., 2017)

- Thiếu sụ theo đuổi BPR và tài trọ" (Al-Mashari \& Zairi, 1999; Hasnan et al., 2017)

Quản lý dự án BPR

- Điều chinh chiến lược BPR với chiến lược của công ty (Al-Mashari \& Zairi, 1999; Bui \& Nguyen, 2016; Chang et al., 2010)

- Lập kế hoạch và sử dụng hiệu quả các kỹ thuật quản
- Nhóm BPR không hiệu quả (AlMashari \& Zairi, 1999; Habib, 2013)

- Thiếu co chế tích hơp, việc định nghĩa công việc và phân bổ trách nhiệm không phù hơp (Al-Mashari \& Zairi, 1999; Habib, 2013; Hasnan et al., 2017)
- Việc lập kế hoạch và quản lý dụ án BPR chura phù hơp (Al-Mashari \& Zairi, 1999; Bui \& Nguyen, 2016; Goksoy et al., 2012; Hasnan et al., 


\begin{tabular}{|c|c|}
\hline Các yếu tố thành công & Các yếu tố thất bại \\
\hline $\begin{array}{l}\text { lý dụ án (Al-Mashari \& Zairi, 1999; Herzog et al., 2007) } \\
\text { - Thiết lập mục tiêu và đo luòng kết quả thưc hiện } \\
\text { (Al-Mashari \& Zairi, 1999; Habib, 2013; Hassan- } \\
\text { gholipour et al., 2013) } \\
\text { - Nguồn lưc đầy đủ (Al-Mashari \& Zairi, 1999; } \\
\text { Chang et al., 2010) } \\
\text { - Sủ dụng phuoong pháp BPR thích hợp (Al-Mashari } \\
\text { \& Zairi, 1999; Herzog et al., 2007) } \\
\text { - Định hương và học tập bên ngoài (Al-Mashari \& } \\
\text { Zairi, 1999; Chang et al., 2010) } \\
\text { - Sủ dụng tư vấn hiệu quả (Al-Mashari \& Zairi, 1999; } \\
\text { Bui \& Nguyen, 2016; Hasnan et al., 2017) } \\
\text { - Thiết kế lại quá trình hiệu quả (Al-Mashari \& Zairi, } \\
\text { 1999; Hasnan et al., 2017) } \\
\text { - Tích hợp BPR với các phuoong pháp cải tiến khác } \\
\text { (Al-Mashari \& Zairi, 1999) } \\
\text { - Nhận dạng được các giá trị BPR (Al-Mashari \& } \\
\text { Zairi, 1999; Hassan-gholipour et al., 2013) } \\
\text { - Kiến thức và kỹ năng của nhân viên về quá trình } \\
\text { (Chang et al., 2010; Goksoy et al., 2012; Habib, 2013; } \\
\text { Hasnan et al., 2017) }\end{array}$ & 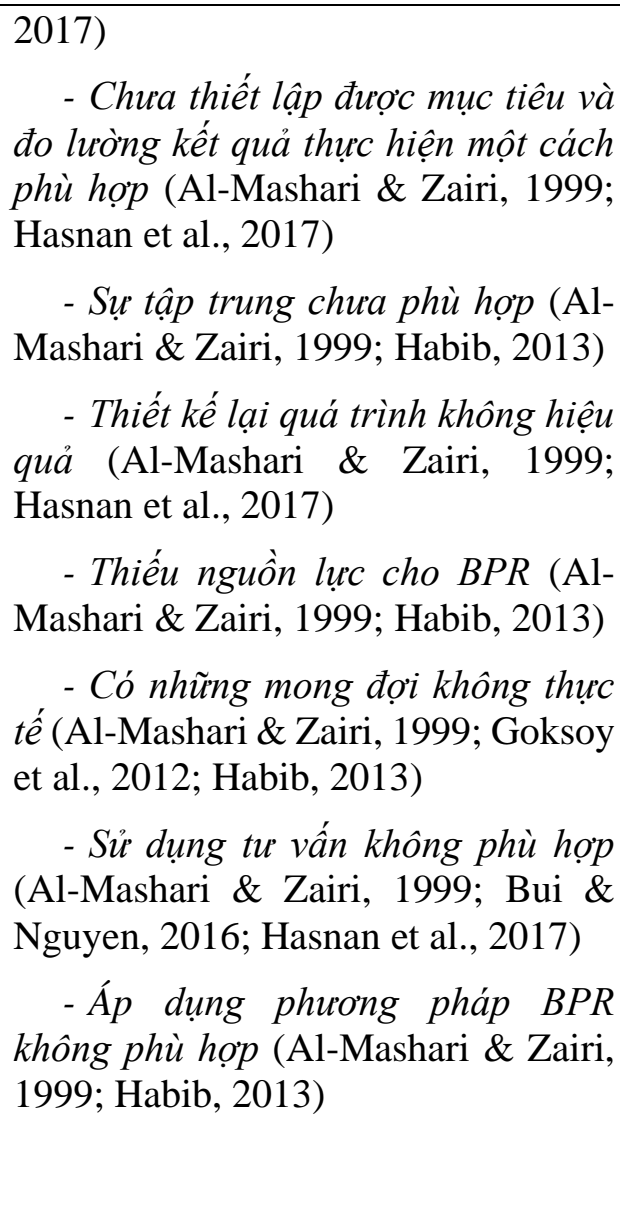 \\
\hline
\end{tabular}

\section{Cơ sở hạ tầng CNTT}

- Sự liên kết cơ sở hạ tầng CNTT với chiến lược BPR (Al-Mashari \& Zairi, 1999; Hassan-gholipour et al., 2013)

- Xây dụng cơ sở ha tầng CNTT hiệu quả (Al-Mashari \& Zairi, 1999; Goksoy et al., 2012; Habib, 2013; Hassan-gholipour et al., 2013; Herzog et al., 2007)

- Các quyết định tìm nguồn cung úng và đầu tu CNTT một cách thich hơp (Al-Mashari \& Zairi, 1999; Goksoy et al., 2012)

- Đo luờng được hiệu quả co sỏ ha tầng CNTT lên BPR (Al-Mashari \& Zairi, 1999; Hasnan et al., 2017; Herzog et al., 2007)

- Tích hơp hệ thống thông tin một cách phù hợp (AlMashari \& Zairi, 1999; Hasnan et al., 2017; Hassangholipour et al., 2013)
- Có vấn đề về các quyết định tìm nguồn cung úng và đầu tu CNTT (AlMashari \& Zairi, 1999)

- Tích hơp hệ thống thông tin chwa phù hơp (Al-Mashari \& Zairi, 1999; Hasnan et al., 2017)

- Phát triển hệ thống thông tin chura phù hơp (Al-Mashari \& Zairi, 1999; Hasnan et al., 2017)

- Tái thiết kế hệ thống thông tin hiện hũu không hiệu quả (Al-Mashari \& Zairi, 1999; Hasnan et al., 2017)

- Quá lệ thuộc vào CNTT dẫn tới chọn nhũng quá trình không hiệu quả để úng dụng CNTT (Goksoy et al., 


\begin{tabular}{|l|l|}
\hline \multicolumn{1}{|c|}{ Các yếu tố thành công } & Các yếu tố thất bại \\
\hline - Tái thiết kế hẹ thống thông tin hiện hưu một cách & 2012) \\
hiệu quả (Al-Mashari \& Zairi, 1999; Habib, 2013; & \\
Hasnan et al., 2017)
\end{tabular}

Nguồn: Tự tổng hợp

\section{Bảng 4}

Một số tình huống triển khai BPR thành công trên thế giới và Việt Nam

\begin{tabular}{|c|c|c|c|c|}
\hline Công ty & $\begin{array}{c}\text { Quá } \\
\text { trình }\end{array}$ & Sụ thay đổi & Lọi ích đạt được & Ngu文n \\
\hline $\begin{array}{l}\text { Deere \& } \\
\text { Co. }\end{array}$ & $\begin{array}{l}\text { Phát triển } \\
\text { sản phẩm }\end{array}$ & $\begin{array}{l}\text { CAD và CAM được sử } \\
\text { dụng cho thiết kế, sản xuất } \\
\text { và quản lý nguyên vật liệu }\end{array}$ & $\begin{array}{l}\text { Giảm chi phí hàng tồn kho } \\
\text { Giảm chi phí sản xuất }\end{array}$ & $\begin{array}{c}\text { Attaran } \\
(2004)\end{array}$ \\
\hline $\begin{array}{l}\text { Dell } \\
\text { Computer }\end{array}$ & $\begin{array}{l}\text { Chuỗi } \\
\text { cung ứng }\end{array}$ & $\begin{array}{l}\text { Công nghệ Internet được sử } \\
\text { dụng để thực hiện phân } \\
\text { phối các sản phẩm theo yêu } \\
\text { cầu cá nhân với mục tiêu } 5 \\
\text { ngày hoặc ít hơn }\end{array}$ & $\begin{array}{l}\text { Giảm hàng tồn kho từ } 13 \text { xuống } \\
\text { còn } 5 \text { ngày, và tiết kiệm } 50 \text { triệu } \\
\text { USD }\end{array}$ & $\begin{array}{l}\text { Attaran } \\
(2004)\end{array}$ \\
\hline $\begin{array}{l}\text { FedEx } \\
\text { Corp. }\end{array}$ & Mua sắm & $\begin{array}{l}\text { Công nghệ Internet được sử } \\
\text { dụng để tự động hóa và hợp } \\
\text { lý hóa toàn bộ quá trình } \\
\text { mua sắm }\end{array}$ & $\begin{array}{l}\text { Thời gian chu kỳ mua đã giảm } \\
\text { từ } 20 \% \text { xuống còn } 70 \% \\
\text { Số lượng nhà cung cấp đã giảm } \\
\text { hơn một nửa } \\
\text { Dịch vụ tốt hơn cho nhân viên }\end{array}$ & $\begin{array}{l}\text { Attaran } \\
(2004)\end{array}$ \\
\hline $\begin{array}{l}\text { Công ty } \\
\text { Mutual } \\
\text { Benefit } \\
\text { Life } \\
\text { (MBL) }\end{array}$ & $\begin{array}{l}\text { Xử lý } \\
\text { đơn của } \\
\text { khách } \\
\text { hàng }\end{array}$ & $\begin{array}{l}\text { Mạng máy tính và cơ sở dữ } \\
\text { liệu được dùng để xử lý và } \\
\text { chia sẻ các thông tin khác } \\
\text { nhau }\end{array}$ & $\begin{array}{l}\text { MBL có thể thực hiện một đơn } \\
\text { bảo hiểm trong ít nhất là } 4 \text { giờ } \\
\text { và trung bình quay vòng chỉ mất } \\
2-5 \text { ngày. } \\
\text { Công ty đã loại bỏ } 100 \text { vị trí văn } \\
\text { phòng và có thể xử lý nhiều hơn } \\
\text { gấp đôi đơn bảo hiểm trước đây. }\end{array}$ & $\begin{array}{l}\text { Asli và } \\
\text { Özalp } \\
(2010)\end{array}$ \\
\hline $\begin{array}{l}\text { Công ty } \\
\text { Ford } \\
\text { Motor }\end{array}$ & $\begin{array}{l}\text { Quá trình } \\
\text { mua hàng }\end{array}$ & $\begin{array}{l}\text { Xây dựng một cơ sở dữ liệu } \\
\text { trực tuyến }\end{array}$ & $\begin{array}{l}\text { Số lượng nhân viên tại bộ phận } \\
\text { mua hàng giảm từ } 500 \text { người } \\
\text { xuống còn } 125 \text { người và hiệu } \\
\text { suất được cải thiện đáng kề. }\end{array}$ & $\begin{array}{l}\text { Asli và } \\
\text { Özalp } \\
(2010)\end{array}$ \\
\hline $\begin{array}{l}\text { Công ty } \\
\text { Taco Bell }\end{array}$ & $\begin{array}{l}\text { Cấp quản } \\
\text { lý } \\
\text { Mặt bằng } \\
\text { Tiếp thị }\end{array}$ & $\begin{array}{l}\text { Giảm cấp quản lý } \\
\text { Bố trí lại mặt bằng } \\
\text { Phát triến cách thức sơ chế } \\
\text { một cách tập trung để nhà } \\
\text { hàng có thể chú trọng vào } \\
\text { việc bán hàng hơn là chế } \\
\text { biến } \\
\text { Xây dựng hệ thống quản lý } \\
\text { thông tin mới để theo dõi } \\
\text { doanh số từng phút một }\end{array}$ & $\begin{array}{l}\text { Taco Bell đã phát triển từ } 1500 \\
\text { nhà hàng vào năm } 1983 \text { lên } \\
3600 \text { nhà hàng vào năm } 1993 \text {. } \\
\text { Doanh thu trong } 10 \text { năm từ } 1983 \\
\text { đến } 1993 \text { tăng từ } 500 \text { triệu lên } 3 \\
\text { tỷ USD, tăng trưởng } 22 \% / \text { năm. } \\
\text { Lợi nhuận tăng } 31 \% / \text { năm. }\end{array}$ & $\begin{array}{l}\text { Rootinc } \\
(2012)\end{array}$ \\
\hline $\begin{array}{l}\text { Nhà máy } \\
\text { Nestle } \\
\text { Đồng Nai }\end{array}$ & Sản phẩm & $\begin{array}{l}\text { Giảm lãng phí của dòng sản } \\
\text { phẩm Gia vị và Cà phê }\end{array}$ & $\begin{array}{l}\text { Chi phí của xưởng Gia vị và Cà } \\
\text { phê năm } 2015 \text { thấp hơn } 2014 \text { là } \\
6 \%\end{array}$ & $\begin{array}{l}\text { Bui và } \\
\text { Nguyen } \\
(2016)\end{array}$ \\
\hline
\end{tabular}




\begin{tabular}{|c|c|c|c|c|}
\hline Công ty & $\underset{\text { trình }}{\text { Quá }}$ & Sụ thay đổi & Lọi ích đạt đực & Nguồn \\
\hline $\begin{array}{l}\text { Công ty } \\
\text { CP SX và } \\
\text { XK Cao } \\
\text { su Phú An }\end{array}$ & $\begin{array}{l}\text { Nơi làm } \\
\text { việc ở } \\
\text { khu vực } \\
\text { văn } \\
\text { phòng và } \\
\text { sản xuất }\end{array}$ & $\begin{array}{l}\text { Sắp xếp lại nơi làm việc, } \\
\text { quy trình công việc đề giảm } \\
\text { thời gian tìm kiếm tài liệu, } \\
\text { vật tư, sử dụng mặt bằng } \\
\text { hiệu quả và giảm thời gian } \\
\text { vận chuyển hàng. }\end{array}$ & $\begin{array}{l}\text { Chi phí vận hành giảm } \\
\text { Dễ thực hiện công việc hơn } \\
\text { Thời gian thực hiện công việc } \\
\text { giảm } \\
\text { Năng suất lao động tăng }\end{array}$ & $\begin{array}{c}\text { Bui và } \\
\text { Nguyen } \\
\text { (2016) }\end{array}$ \\
\hline
\end{tabular}

Nguồn: Tự tổng hợp

\subsection{Quy trình thục hiện BPR}

Có nhiều nghiên cứu đề xuất các bước thực hiện BPR như là quy trình gồm 3 giai đoạn với 9 bước của GAO (1997), quy trình 5 bước của Muthu, Whitman, và Cheraghi (1999), quy trình 8 bước của Zygiaris (2000), quy trình 15 bước của Lee và Chuah (2001). Các quy trình này được so sánh về ưu nhược điểm ở Bảng 5.

\section{Bảng 5}

So sánh ưu và nhược điểm của các quy trình thực hiện BPR

\begin{tabular}{|c|c|c|c|}
\hline Quy trình & U’u điểm & Nhược điểm & Úng dụng \\
\hline $\begin{array}{l}\text { GAO } \\
(1997) \\
(3 \text { giai } \\
\text { doạn, } 9 \\
\text { bước) }\end{array}$ & $\begin{array}{l}\text { Được xây dựng tổng quát cho tất cả các doanh } \\
\text { nghiệp, ngành nghề. } \\
\text { Đánh giá lại tổng thể doanh nghiệp, cho lãnh } \\
\text { đạo doanh nghiệp nhìn lại một cách toàn diện } \\
\text { các vấn đề mà doanh nghiệp gặp phải. } \\
\text { Nhấn mạnh đến cải tiến dịch vụ khách hàng và } \\
\text { giải quyết các vấn đề về chi phí cho doanh } \\
\text { nghiệp. } \\
\text { Tiếp cận vấn đề theo hàng ngang: sự liên kết } \\
\text { của các phòng ban chức năng, sự liên kêt của } \\
\text { quá trình vận hành công việc. }\end{array}$ & $\begin{array}{l}\text { Khung đánh giá khá } \\
\text { tổng quát, để có thể triển } \\
\text { khai áp dụng cần sự hiệu } \\
\text { chỉnh riêng cho từng } \\
\text { doanh nghiệp. } \\
\text { Quy trình phức tạp. }\end{array}$ & $\begin{array}{l}\text { Sử dụng phổ } \\
\text { biến ở Mỹ, đặc } \\
\text { biệt hỗ trợ cho } \\
\text { các nhà tư vấn } \\
\text { cho các doanh } \\
\text { nghiệp thực hiện } \\
\text { BPR. }\end{array}$ \\
\hline $\begin{array}{l}\text { Muthu et } \\
\text { al. (1999) } \\
\text { (5 bước) }\end{array}$ & $\begin{array}{l}\text { Quy trình đơn giản. } \\
\text { Thuận lợi cho mô hình hóa các quá trình dựa } \\
\text { trên CNTT. } \\
\text { Nhấn mạnh đến ứng dụng giải pháp CNTT. }\end{array}$ & $\begin{array}{l}\text { Các bước thực hiện khá } \\
\text { chung, chưa có những } \\
\text { hướng dẫn cụ thể. } \\
\text { Chưa nhấn mạnh sự cam } \\
\text { kết và quyết tâm theo } \\
\text { đuồi BPR của ban lãnh } \\
\text { đạo. }\end{array}$ & $\begin{array}{l}\text { Được áp dụng } \\
\text { trong một số } \\
\text { doanh nghiệp } \\
\text { của Anh. }\end{array}$ \\
\hline $\begin{array}{l}\text { Zygiaris } \\
(2000) \\
(8 \text { buóc })\end{array}$ & $\begin{array}{l}\text { Quy trình đơn giản. } \\
\text { Có bước chuẩn bị thực hiện BPR. } \\
\text { Các bước hướng dẫn khá cụ thể. } \\
\text { Nhấn mạnh đến ứng dụng giải pháp CNTT. }\end{array}$ & $\begin{array}{l}\text { Hướng dẫn thực hiện } \\
\text { các bước không chi tiết } \\
\text { và cụ thể so với của } \\
\text { GAO (1997). }\end{array}$ & $\begin{array}{l}\text { Được ứng dụng } \\
\text { tại IBM, AT\&T, } \\
\text { Sony, General } \\
\text { Electric... }\end{array}$ \\
\hline $\begin{array}{l}\text { Lee và } \\
\text { Chuah } \\
(2001)\end{array}$ & $\begin{array}{l}\text { Đây là quy trình lặp, nhằm mục tiêu cải tiến } \\
\text { liên tục các quá trình, tìm ra và triến khai giải } \\
\text { quyết tất cả các vấn đề để tăng năng lực cạnh }\end{array}$ & $\begin{array}{l}\text { Quy trình thiếu bước } \\
\text { đánh giá lại các mục tiêu } \\
\text { chiến lược của tổ chức. }\end{array}$ & $\begin{array}{l}\text { Được triển khai } \\
\text { áp dụng thực tế } \\
\text { vào ngành công }\end{array}$ \\
\hline
\end{tabular}




\begin{tabular}{|c|c|c|c|}
\hline Quy trình & U’u điểm & Nhược điểm & Ứng dụng \\
\hline $\begin{array}{l}\text { (5 giai } \\
\text { đoạn, } 15 \\
\text { bước) }\end{array}$ & $\begin{array}{l}\text { tranh và tăng hiệu quả hoạt động cho tổ chức. } \\
\text { Quy trình này được kết hợp từ } 3 \text { phương pháp } \\
\text { mới, đang được sự quan tâm hiện nay của } \\
\text { nhiều chuyên gia nên tính ứng dụng cao. } \\
\text { Có thể áp dụng cho tất cả các lĩnh vực (sản } \\
\text { xuất, kinh doanh,...) của doanh nghiệp. } \\
\text { Tiếp cận quá trình cải tiến theo hàng dọc: từng } \\
\text { phòng ban chức năng, từng lĩnh vực cụ thể,... }\end{array}$ & $\begin{array}{l}\text { Các hướng dẫn nội dung } \\
\text { của từng bước còn chưa } \\
\text { cụ thể. }\end{array}$ & $\begin{array}{l}\text { nghiệp tại Hồng } \\
\text { Kong. }\end{array}$ \\
\hline
\end{tabular}

Nguồn: Bui và Nguyen (2016)

Giai đoạn 1

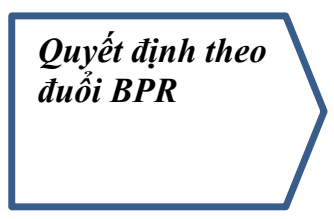

\begin{tabular}{|l|}
\hline $\begin{array}{l}\text { Buớc 1: Đánh giá lại } \\
\text { mục tiêu và chiến } \\
\text { lược }\end{array}$ \\
\begin{tabular}{|l|}
\hline \multicolumn{1}{|c|}{$\downarrow$} \\
Buóóc 2: Xác định \\
vầ về kết quả \\
thực hiện và thiết lập \\
mục tiêu cải tiến
\end{tabular} \\
\hline \multicolumn{1}{|c|}{$\downarrow$} \\
\hline $\begin{array}{l}\text { Buớc 3: Quyết định } \\
\text { việc triển khai BPR }\end{array}$ \\
\hline
\end{tabular}

Giai đoạn 2
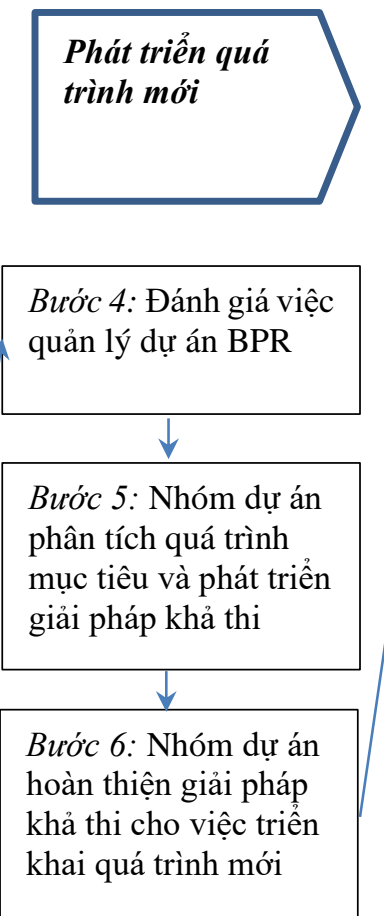

Giai đoạn 3

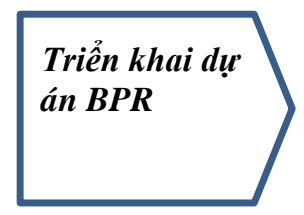

Buớc 7: Nhóm chức năng triển khai giải pháp dự án BPR

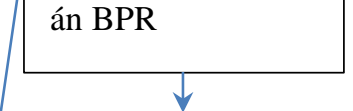

Bước 8: Ban điều hành chức năng đánh giá các vấn đề về quản lý thay đổi

\section{Giai đoạn 4}

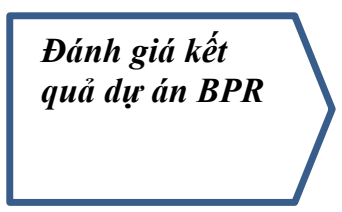

Bước 9: Đánh giá kết quả đạt được của quá trình mới

\begin{tabular}{l}
$\downarrow$ \\
$\begin{array}{l}\text { Bước 10: Đánh giá } \\
\text { những thay đồi sau } \\
\text { khi thực hiện dự } \\
\text { án BPR }\end{array}$ \\
\hline
\end{tabular}

Hình 1. Quy trình thực hiện BPR

Nguồn: Bui và Nguyen (2016)

Trong các quy trình trên thì quy trình của GAO (1997) mặc dù quy trình phức tạp hơn so với các quy trình khác, nhưng lại đầy đủ và chi tiết nhất. Ngoài ra, quy trình này được các nhà tư vấn áp dụng phổ biến ở Mỹ. Do đó, Bui và Nguyen (2016) đã hiệu chỉnh quy trình của GAO (1997) để đề xuất áp dụng cho các doanh nghiệp ở Việt Nam. Quy trình thực hiện BPR của Bui và Nguyen (2016) gồm 4 giai đoạn và 10 bước ở Hình 1. Quy trình này đã được triển khai thử nghiệm tại một số doanh nghiệp Việt Nam và kết quả đem lại khá tích cực. Nhưng hạn chế của nghiên cứu này là chưa tích hợp các công cụ và kỹ thuật hỗ trợ cho việc triển khai từng bước trong quy trình BPR. 


\section{Các công cụ hỗ trọ}

Mặc dù, các nghiên cứu về BPR khá nhiều, nhưng các nghiên cứu về công cụ và kỹ thuật hỗ trợ cho BPR rất hạn chế. Kết quả là một số tác giả và chuyên gia tư vấn đã theo đuổi việc sử dụng nhiều công cụ khác nhau để ứng dụng cho BPR. Những công cụ và kỹ thuật được đề xuất là quá trình trực quan, mô hình hóa và lập bản đồ quá trình, quản lý sự thay đổi, Benchmarking, tập trung vào quá trình và khách hàng, chẩn đoán và giải quyết vấn đề, tạo mẫu và mô phỏng quá trình, quản lý dự án, đo lường quá trình (Goksoy et al., 2012). Tuy nhiên, các công cụ và kỹ thuật này khá tổng quát và chưa được tích hợp vào từng bước của quy trình $\mathrm{BPR}$. Theo Gadd và Oakland (1996) và Chang (1994), việc tích hợp BPR với các hệ thống quản lý chất lượng khác là cần thiết và sẽ đem lại hiệu quả cho các dự án BPR. Vì vậy, việc tích hợp các công cụ và kỹ thuật của các hệ thống quản lý khác theo từng bước của BPR được đề xuất trong Bảng 6.

Phân tích SWOT (Strength - Weakness - Opportunity - Thread): là một công cư được sử dụng để lập kế hoạch chiến lược và quản lý chiến lược trong các tổ chức và nó có thể được sử dụng hiệu quả để xây dựng chiến lược tổ chức và chiến lược cạnh tranh (Gürel, 2017).

Bản đồ chiến luợc (Strategy map): Bản đồ chiến lược là một sơ đồ ghi lại các mục tiêu chiến lược ưu tiên được một doanh nghiệp hoặc một nhóm quản lý theo đuổi. Đây là một phần quan trọng của thẻ điểm cân bằng (Niven, 2010).

Chuẩn đối sánh (Benchmarking): là một quá trình liên tục và có hệ thống để so sánh các sản phẩm, dịch vụ, quy trình và kết quả với các tổ chức được chọn làm chuẩn, nhằm mục đích cải thiện kết quả bằng cách xác định, thích nghi và thực hiện các phương pháp thực hành tốt nhất (Edith Cowan University, 2011).

DMAIC: là một tiến trình trong hệ thống Lean Six Sigma gồm 5 bước: xác định (Define), đo lường (Measure), phân tích (Analyze), cải tiến (Improve) và kiểm soát (Control). Lợi ích khi áp dụng DMAIC là cải tiến được thời gian đáp ứng đối với nhu cầu của khách hàng, giảm tồn kho, giảm yêu cầu vốn lưu động, cải tiến năng suất, giảm chi phí sản xuất, góp phần thay đổi văn hóa công ty một cách tích cực (Bui, 2011).

FMEA (Failure Modes and Effects Analysis): Phân tích các dạng sai hỏng và tác động là một phương pháp điều tra để xác định một sản phẩm, quá trình hoặc hệ thống sai hỏng như thế nào và ảnh hưởng của những sai hỏng này, từ đó lựa chọn sai hỏng nào cần ưu tiên cải tiến (Snee \& Rodebaugh, 2007).

QFD (Quality Function Deployement): Triển khai chức năng chất lượng là một kỹ thuật xây dựng cấu trúc và tổ chức cho quá trình phát triển và sản xuất ra sản phẩm. QFD xuất phát từ điều khách hàng mong muốn, chứ không phải từ đổi mới công nghệ. QFD gồm có 4 ma trận theo các bước từ thiết kế sản phẩm cho đến thiết kế quá trình sản xuất để làm gia tăng tính đặc trưng của sản phẩm. Tuy nhiên, phần ứng dụng chính của QFD phần lớn tập trung ở ma trận thứ nhất là ngôi nhà chất lượng (HOQ) (Bui \& Nguyen, 2017).

Kaizen là một từ của Nhật nhưng đã trở nên phổ biến ở nhiều quốc gia trên thế giới. Có hai yếu tố xây dựng kaizen là cải tiến/thay đổi cho tốt hơn và đang diễn ralliên tục. Kaizen là một quá trình cải tiến đang diễn ra, không bao giờ kết thúc (Prošić, 2011).

$5 S$ là một chương trình nâng cao năng suất rất phổ biến ở Nhật Bản và dần dần trở nên phổ biến ở nhiều nước khác. $5 \mathrm{~S}$ là chữ cái đầu của các từ tiếng Nhật "Seri", "Seiton", "Seiso", 
Seiketsu" Và "Shitsuke", tạm dịch sang tiếng Việt là "Sàng Lọc", "Sắp xếp", Sạch sẽ, "Săn Sóc", "Sẵn Sàng" (Dang, 2016).

VSM (Value Stream Mapping): Sơ đồ chuỗi giá trị là một sơ đồ biểu thị sự luân chuyển của dòng thông tin, và cách mà nó được quản lý, kiểm soát hoặc sự tác động của dòng thông tin lên dòng nguyên vật liệu. VSM được sử dụng trong Lean để thiết kế lại các hệ thống sản xuất (Yuvamitra, Lee, \& Dong, 2017).

7 công cu chất lượng co bản: là các công cụ đơn giản có thể được sử dụng để giảm bớt các sai hỏng và cải thiện chất lượng của quá trình. Chúng bao gồm lưu đồ, bảng kiểm tra, biểu đồ tần số, biểu đồ Pareto, biểu đồ phân tán, biểu đồ nhân quả, và biểu đồ kiểm soát (Bui \& Nguyen, 2017).

Việc tích hợp các công cụ và kỹ thuật hỗ trợ trong Bảng 6 cho thấy các bước của BPR xuyên suốt từ chiến lược của tổ chức, đến việc triển khai dự án thay đổi/cải tiến và sau đó đánh giá lại tác động của dự án đến sự thay đổi của tổ chức. Tùy theo đặc điểm của dự án cải tiến/ thay đổi mà các doanh nghiệp có thể chọn một vài công cụ và kỹ thuật hỗ trợ phù hợp nhằm đem lại hiệu quả tốt nhất cho việc thực hiện BPR.

\section{Bảng 6}

Các công cụ và kỹ thuật hỗ trợ khi thực hiện BPR

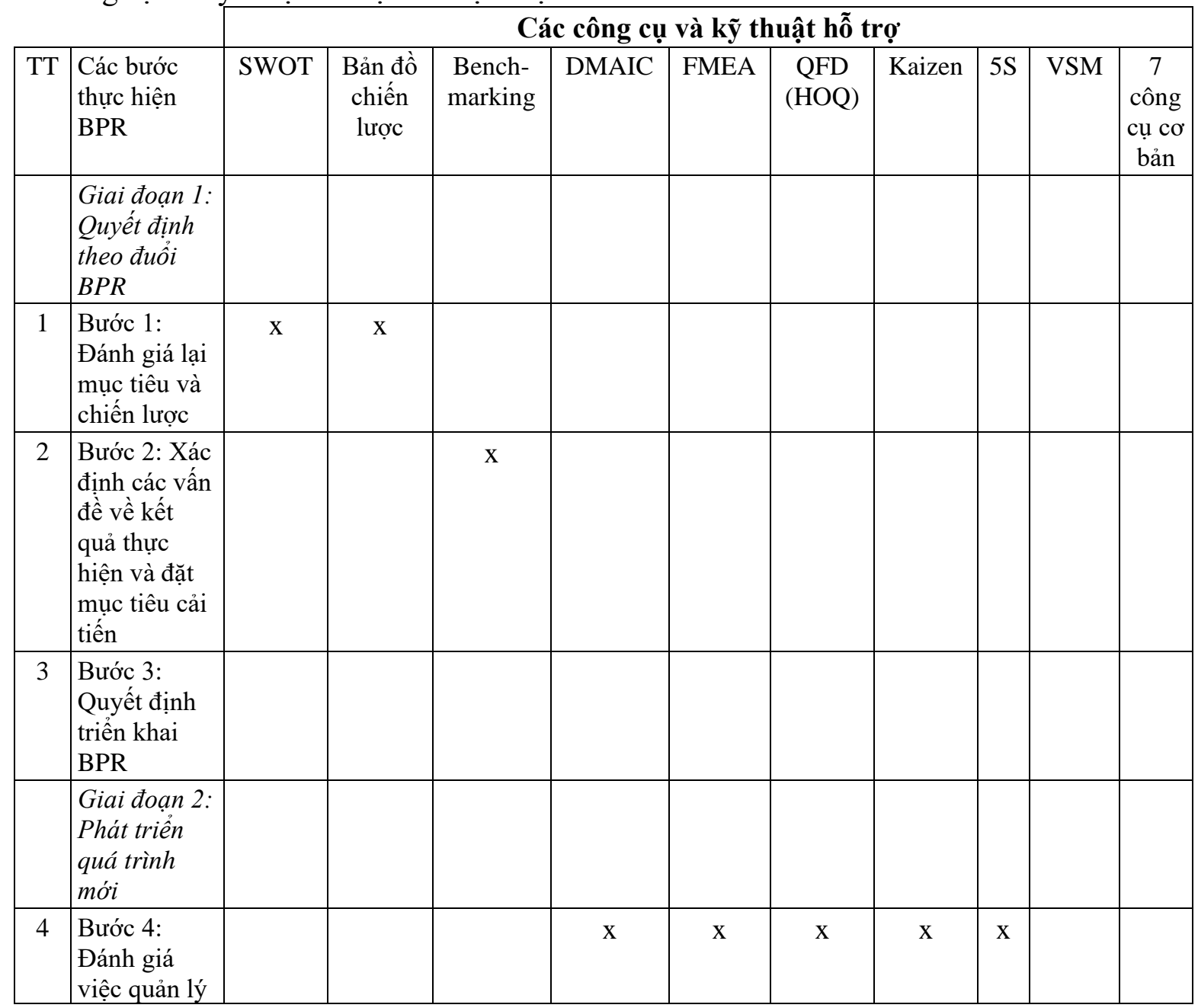




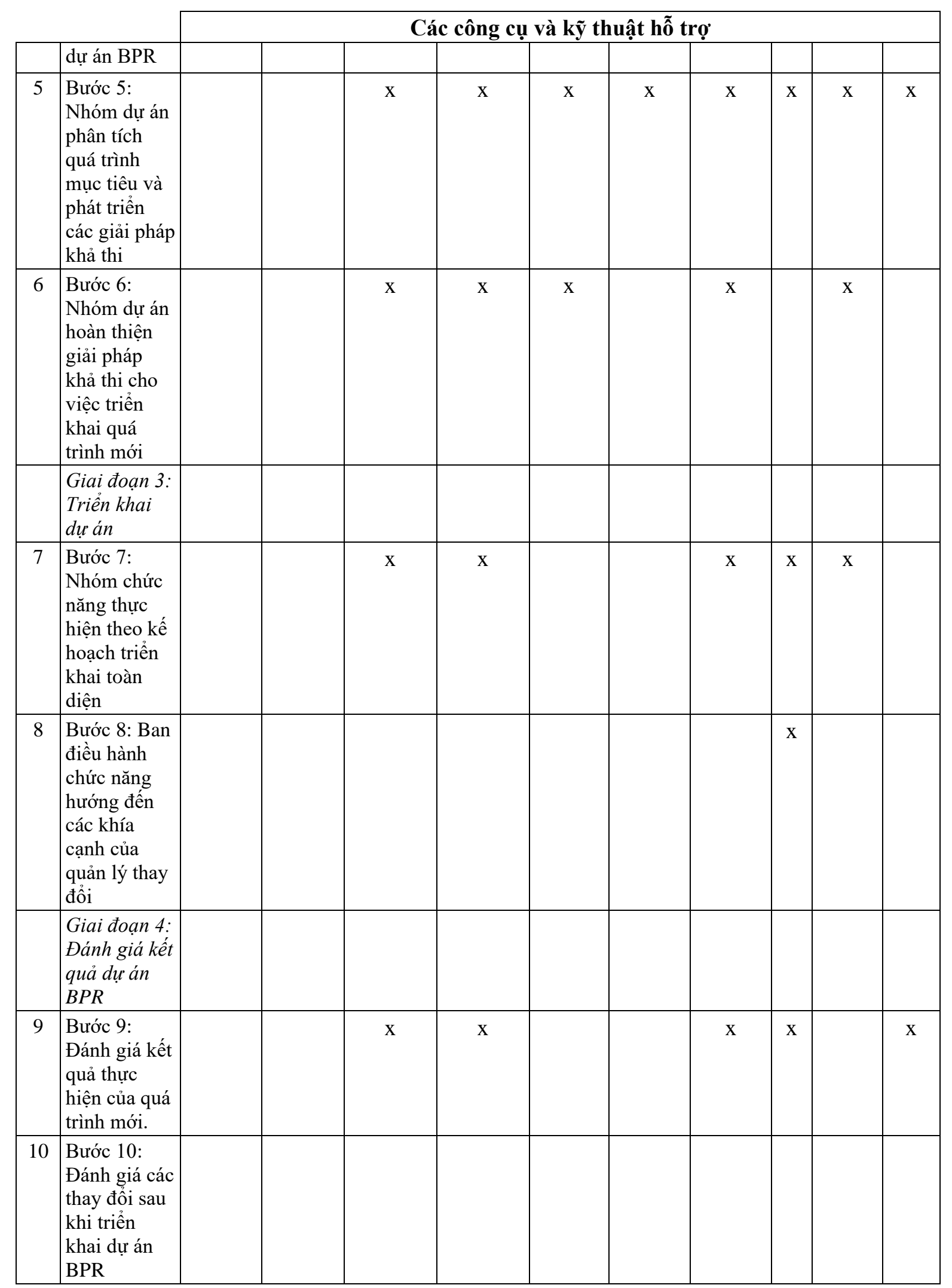

Ghi chú: $\mathrm{x}$ thể hiện các công cụ có thể hỗ trợ cho các bước của BPR Nguồn: Tự tổng hợp 


\section{Kết luận}

Trong môi trường cạnh tranh gay gắt hiện nay, việc tập trung vào khách hàng trọng tâm, thiết kế quy trình vượt trội và khả năng lãnh đạo mạnh mẽ và năng động là những thành phần quan trọng cho sự thành công của bất kỳ tổ chức kinh doanh nào. BPR là chìa khóa mà mọi tổ chức nên sở hữu để đạt được những điều kiện tiên quyết để thành công. Bài báo đã đưa ra được các nội hàm chính của $\mathrm{BPR}$ gồm tư duy lại nền tảng, thiết kế lại căn bản, quá trình kinh doanh, và thay đổi đáng kể. CNTT chính là nhân tố có thể giúp tạo ra những thay đổi căn bản và đáng kể cho các quá trình kinh doanh khi thực hiện BPR. Những kinh nghiệm trên thế giới và Việt Nam đã được tổng hợp dựa trên các yếu tố thành công và thất bại khi thực hiện BPR và các tình huống triển khai BPR thành công. Bài báo cũng đề xuất sự tích hợp các công cụ và kỹ thuật trong các hệ thống quản lý khác với các bước trong quy trình thực hiện BPR để việc thực hiện $\mathrm{BPR}$ trở nên thuận lợi và dễ dàng hơn cho các doanh nghiệp Việt Nam.

Hạn chế của bài báo này là chưa triển khai thử nghiệm về sự tích hợp giữa các bước $\mathrm{BPR}$ và các công cụ hỗ trợ. Do đó, hướng nghiên cứu tiếp theo là sẽ tiến hành thử nghiệm ở một số doanh nghiệp ở Việt Nam. Qua đó sẽ đánh giá được những thuận lợi, khó khăn và rút ra những bài học kinh nghiệm khi triển khai các bước BPR và các công cụ hỗ trợ.

\section{LỜI CÁM ƠN}

Nghiên cứu được tài trợ bởi Trường Đại học Bách khoa - ĐHQG-HCM trong khuôn khổ Đề tài mã số To-QLCN-2017-18.

\section{Tài liệu tham khảo}

Adeyemi, S., \& Aremu, M. A. (2008). Impact assessment of business process reengineering on organizational performance. European Journal of Social Sciences, 7(1), 115-125.

Al-Mashari, M., \& Zairi, M. (1999). BPR implementation process: An analysis of key success and failure factors. Business Process Management Journal, 5(1), 87-112.

Asli, E., \& Özalp, V. (2010). Is the Business Process Reengineering (BPR) proved itself to be a trustable change management approach for multinational corporations? Case studies from the literature. Journal of Aeronautics and Space Technologies, 4(4), 23-30.

Attaran, M. (2004). Exploring the relationship between information technology and business process reengineering. Information \& Management, 41(5), 529-684.

Bui, H. N. (2011). Sản xuất theo LEAN [Manufactured by LEAN]. Ho Chi Minh, Vietnam: NXB Đại học Quốc Gia TPHCM.

Bui, H. N., \& Nguyen, L. T. Q. (2016). Nghiên cúu công cu chẩn đoán và lộ trình tái cấu trúc các doanh nghiệp Việt Nam trong giai đoạn chuyển đổi và tái cấu trúc nền kinh tế [Research on diagnostic tools and roadmap for restructuring Vietnamese businesses in the period of economic transition and restructuring]. Retrieved October 10, 2017, from Mạng Thông tin Khoa học \& Công nghệ website: http://library.cesti.gov.vn/opac/search/detail2.asp?aID=3\&ID=227538\&title=Nghi\%C3 $\% \mathrm{AAn}+\mathrm{c} \% \mathrm{E} 1 \% \mathrm{BB} \% \mathrm{~A} 9 \mathrm{u}+\mathrm{c} \% \mathrm{C} 3 \% \mathrm{~B} 4 \mathrm{ng}+\mathrm{c} \% \mathrm{E} 1 \% \mathrm{BB} \% \mathrm{~A} 5+\mathrm{ch} \% \mathrm{E} 1 \% \mathrm{BA} \% \mathrm{~A} 9 \mathrm{n}+\% \mathrm{C} 4 \%$ $910 \% \mathrm{C} 3 \% \mathrm{~A} 1 \mathrm{n}+\mathrm{v} \% \mathrm{C} 3 \% \mathrm{~A} 0+1 \% \mathrm{E} 1 \% \mathrm{BB} \% 99+\operatorname{tr} \% \mathrm{C} 3 \% \mathrm{ACnh}+\mathrm{t} \% \mathrm{C} 3 \% \mathrm{~A} 1 \mathrm{i}+\mathrm{c} \% \mathrm{E} 1 \% \mathrm{BA}$ 
$\%$ A5u+tr\%C3\%BAc+c\%C3\%A1c+doanh+nghi $\%$ E1\%BB\%87p+Vi\%E1\%BB\%87t+Na $\mathrm{m}+$ trong+giai+\% $4 \% 910 \% \mathrm{E} 1 \% \mathrm{BA} \% \mathrm{~A} 1 \mathrm{n}+\mathrm{chuy} \% \mathrm{E} 1 \% \mathrm{BB} \% 83 \mathrm{n}+\% \mathrm{C} 4 \% 91 \% \mathrm{E} 1 \% \mathrm{BB}$ $\% 95 \mathrm{i}+\mathrm{v} \% \mathrm{C} 3 \% \mathrm{~A} 0+\mathrm{t} \% \mathrm{C} 3 \% \mathrm{~A} 1 \mathrm{i}+\mathrm{c} \% \mathrm{E} 1 \% \mathrm{BA} \% \mathrm{~A} 5 \mathrm{u}+\mathrm{tr} \% \mathrm{C} 3 \% \mathrm{BAc}+\mathrm{n} \% \mathrm{E} 1 \% \mathrm{BB} \% 81 \mathrm{n}+\mathrm{kin}$ $\mathrm{h}+\mathrm{t} \% \mathrm{E} 1 \% \mathrm{BA} \% \mathrm{BF}+\% 2 \mathrm{~F}++++\% \mathrm{C} 4 \% 90 \% \mathrm{E} 1 \% \mathrm{BA} \% \mathrm{~A} 1 \mathrm{i}+\mathrm{h} \% \mathrm{E} 1 \% \mathrm{BB} \% 8 \mathrm{Dc}+\mathrm{B} \% \mathrm{C} 3 \% \mathrm{~A}$ 1ch+Khoa+TP\%2E+H\%E1\%BB\%93+Ch\%C3\%AD+Minh\%3B+B\%C3\%B9i+Nguy\% $\mathrm{C} 3 \% \mathrm{AAn}+\mathrm{H} \% \mathrm{C} 3 \% \mathrm{~B} 9 \mathrm{ng} \% 2 \mathrm{C}+\mathrm{Nguy} \% \mathrm{E} 1 \% \mathrm{BB} \% 85 \mathrm{n}+\mathrm{Th} \% \mathrm{C} 3 \% \mathrm{BAy}+\mathrm{Qu} \% \mathrm{E} 1 \% \mathrm{BB} \% \mathrm{~B}$ 3nh+Loan

Bui, H. N., \& Nguyen, L. T. Q. (2017). Quản lý chất lương [Quality management]. Ho Chi Minh, Vietnam: NXB Đại học Quốc Gia TPHCM.

Carr, D. K., \& Johansson. J. (1995). Best practices in re-engineering: What works and what doesn't in the re-engineering process. New York, NY: Coopers \& Lybrand.

Chang, J., Levy, M., \& Powell, P. (2009). Process re-engineering success in small and medium sized enterprises. International Journal of Enterprise Information Systems, 5(3), 14-26.

Chang, J., Levy, M., \& Powell, P. (2010). Process re-engineering success in small and medium sized enterprises. In M. M. Cruz-Cunha (Ed.), Enterprise information systems for business integration in SMEs: Technological, organizational, and social dimensions (pp. 363-375). Hershey, PA: IGI Global.

Chang, R. Y. (1994). Improve processes, reengineer them, or both? Training and Development, 48(3), 54-58.

Cole, R. E. (1994). Reengineering the corporation: A review essay. Quality Management Journal, 1(4), 77-85.

Dang, D. T. (2016). Tài liệu đào tạo 5s [Training materials 5s]. Retrieved October 12, 2017, from Chi cục Tiêu chuẩn đo lường chất lượng TP.HCM website: http://www.chicuctdc.gov.vn/

Davenport, T. H. (1993). Need radical innovation and continuous improvement? Planning Review, 21(3), 6-12.

Davenport, T. H., \& Short, J. E. (1990). The new industrial engineering: Information technology and business process redesign. Sloan Management Review, 31(4), 11-27.

Dubrovski, D. (2005). Restructuring and business reengineering in integrative processes. Managing Global Transitions, 3(1), 71-93.

Edith Cowan University. (2011). Benchmarking policy. Retrieved October 15, 2017, from http://www.ecu.edu.au/GPPS/ policies_db/tmp/ad075.pdf

Furey, T. R. (1993). A six-step guide to process reengineering. Strategy \& Leadership, 21(2), 20-23.

Gadd, K., \& Oakland, J. (1996). Chimera or culture? Business process re-engineering for total quality management. Quality Management Journal, 3(3), 20-38.

Gamar, J. J., \& Agrawal, B.S. (2015). Literature review of BPR modelling techniques and tools. International Journal of Computer \& Mathematical Sciences, 4(6), 1-7.

GAO. (1997). Business process reengineering assessment guide (3rd ed.). Retrieved October 20, 2017, from United States General Accounting Office website: https://www.gao.gov/products/AIMD-10.1.15 
Goksoy, A., Ozsoy, B., \& Vayvay, O. (2012). Business process reengineering: Strategic tool for managing organizational change an application in a multinational company. International Journal of Business and Management, 7(2), 89-112.

Gürel, E. (2017). SWOT analysis: A theoretical review. Journal of International Social Research, 10(51), 994-1006. doi:10.17719/jisr.2017.1832

Habib, M. N. (2013). Understanding critical success and failure factors of business process reengineering. International Review of Management and Business Research, 2(1), 1-10.

Hammer, M., \& Champy, J. A. (1993) Reengineering the corporation: A manifesto for business revolution. New York, NY: Harper Collins Publishers.

Hasnan, N., Ringim, K., \& Razalli, M. R. (2017). Assessing the implementation level of business process reengineering factors in Malaysian Islamic banks. Journal of Advanced Research in Business and Management Studies, 7(1), 1-12.

Hassan-gholipour, T., Abbaszadeh, M. A., \& Abtahi, S. M. (2013). Offering an operational framework for measuring the risk level in the implementation of re-engineering projects of business processes. International Journal of Academic Research in Business and Social Sciences, 3(1), 601-615.

Herzog, N. V., Polajnar, A., \& Tonchia, S. (2007). Development and validation of business process reengineering (BPR) variables: A survey research in Slovenian companies. International Journal of Production Research, 45(24), 5811-5834. doi:10.1080/00207540600854992

Lee, K. T., \& Chuah, K. B. (2001). A SUPER methodology for business process improvement: An industrial case study in Hong Kong/China. International Journal of Operations \& Production Management, 21(5/6), 687-706. doi:10.1108/01443570110390408

Lilian, O. O., Uzochukwu, O. C., \& Francisca, O. N. (2015). Business process reengineering and organizational performance of selected automobile firms in Southeast of Nigeria. European Journal of Business, Economics and Accountancy, 3(5), 12-45.

Muthu, S., Whitman, L., \& Cheraghi, S. H. (1999). Business process reengineering: A consolidated methodology. Proceedings of the 4th Annual International Conference on Industrial Engineering Theory, Applications and Practice.

Nissen, M. E. (1996). A focused review of the reengineering literature: Expert frequently asked questions (FAQs). Quality Management Journal, 3(3), 52-66.

Niven, P. R. (2010). Balanced scorecard step-by-step: Maximizing performance and maintaining results. Hoboken, NJ: John Wiley \& Sons.

Omidi, A., \& Khoshtinat, B. (2016). Factors affecting the implementation of business process reengineering: Taking into account the moderating role of organizational culture (Case study: Iran air). Procedia Economics and Finance, 36, 425-432.

Ozcelik, Y. (2010). Do business process reengineering projects payoff? Evidence from the United States. International Journal of Project Management, 28(1), 7-13.

Petrozzo, D. P., \& Stepper, J. C. (1994). Successful reengineering. New York, NY: Van Nostrand Reinhold.

Prošić, S. (2011). Kaizen management philosophy. Proceedings of International Symposium Engineering Management and Competitiveness 2011 (EMC2011), 173-178. 
Rootinc. (2012). Taco Bell's “bold future” transformation - Case study. Retrieved October 20, 2017, from https://www.rootinc.com/pdfs/case-studies/TacoBell_CaseStudy.pdf

Samia, M. S., \& Germaine, H. S. (2008). Business process improvement: empirical assessment and extensions. Business Process Management Journal, 14(6), 778-802.

Sanjay, M. (2013). Business process reengineering: Automation decision points in process reengineering. Bhubaneswar, India: Xavier Institute of Management.

Siha, S. M., \& Saad, G. H. (2008). Business process improvement: Empirical assessment and extensions. Business Process Management Journal, 14(6), 778-802. doi:10.1108/14637150810915973

Snee, R., \& Rodebaugh, W. (2007). Failure modes and effects analysis. Retrieved October 25, 2017, from https://quality-one.com/fmea/

Ursic, D., Anteric, S., \& Mulej, M. (2005). Business process re-engineering in practice - A medium-sized Slovenian company in difficulties. Systemic Practice and Action Research, $18(1), 89-117$.

Yuvamitra, K., Lee, J., \& Dong, K. (2017). Value stream mapping of rope manufacturing: A case study. International Journal of Manufacturing Engineering, 2017(6), 1-11.

Zygiaris, S. (2000). Business process re-engineering - BPR, INNOREGIO: Dissemination of innovation and knowledge management techniques. Retrieved October 28, 2017, from https://www.twirpx.com/file/2076726/ 